\title{
Can a single question about family members' sense of security during palliative care predict their well-being during bereavement? A longitudinal study during ongoing care and one year after the patient's death
}

Anna Milberg ${ }^{1,2}$, Maria Liljeroos ${ }^{1,3,4^{*}}$ (D) and Barbro Krevers ${ }^{1}$

\begin{abstract}
Background: It has been recognised that more evidence about important aspects of family members' sense of security during palliative care is needed. The objectives of the study was: i) to discover what variables are associated with family members feeling secure during palliative care; ii) to develop a model of family members' sense of security during palliative care, and iii) to evaluate if family members' sense of security during ongoing palliative care predicts well-being during bereavement.

Methods: Between September 2009 and October 2010, 227 family members (of patients admitted to six Swedish palliative home care units) participated in the study (participation rate 75\%) during ongoing care and 158 participated also 1 year after the patient's death (70\%). They answered a single question regarding the family members' sense of security during the palliative care period. The question was constructed and validated by the researchers. Data were also collected using other questions and validated instruments and analysed stepwise with Generalized Linear Models (ordinal multinomial distribution and logit link).

Results: Sixteen variables were positively related to family members' sense of security during ongoing palliative care. The five variables with the highest importance were selected into the model (listed in decreasing importance): Family members' mastery; nervousness and stress; self-efficacy; patient having gynaecological cancer; family members' perceived quality of life. Moreover, the family members' sense of security during ongoing palliative care predicted ten variables indicating their well-being 1 year after the patient's death, e.g. psychological well-being, complicated grief symptoms, health related quality of life.
\end{abstract}

Conclusions: The findings reveal possibilities to identify family members at risk of negative adjustment to bereavement in clinical practice and may help to develop interventions to support family members during ongoing palliative care.

Keywords: Family members, Palliative care, Security, Bereavement

\footnotetext{
* Correspondence: maria.liljeroos@liu.se

'Department of Medical and Health Sciences, Linköping University,

Linköping, Sweden

${ }^{3}$ Centre for Clinical Research Sörmland, Uppsala University, Eskilstuna,

Sweden

Full list of author information is available at the end of the article
}

(C) The Author(s). 2019 Open Access This article is distributed under the terms of the Creative Commons Attribution 4.0 International License (http://creativecommons.org/licenses/by/4.0/), which permits unrestricted use, distribution, and reproduction in any medium, provided you give appropriate credit to the original author(s) and the source, provide a link to the Creative Commons license, and indicate if changes were made. The Creative Commons Public Domain Dedication waiver (http://creativecommons.org/publicdomain/zero/1.0/) applies to the data made available in this article, unless otherwise stated. 


\section{Background}

Life-threatening illness often generates considerable distress for family members [1], and having a sense of security can be of great value for them in such situations [2-6]. A definition of security is 'freedom from danger', 'freedom from fear or anxiety', and 'safety'. To feel security in care is of international relevance. Funk et al. [7] found that a conceptualization of security extends beyond trust in individuals to include a generalized sense of institutional trust in the health care system. For family caregivers', it provides security to know that healthcare will be provided when needed by competent professionals and it is of crucial importance, particularly for those, such as palliative family caregivers, that are already in situations that create a fundamental sense of insecurity.

Research has indicated that family members' sense of security can be facilitated in palliative care, e.g. by the acquisition of adequate knowledge about palliative care and possible symptom management, by ensuring the availability of competent professionals with an attitude of open-mindedness, open-heartedness, and a team sensitivity and flexibility in meeting both patients' and families' needs [3, 5-11]. In addition, the importance of family caregivers feeling secure in their own identity and self-worth as caregivers and individuals have also been stressed [12].

Although family members' sense of security during palliative care has been recognised as valuable and research suggesting that such a sense may be facilitated by professionals in palliative care, we have only identified one published study applying a quantitative design and with focus on variables associated with family members being secure/less secure. Igarashi et al. examined associations between end-of-life care in Japan and a sense of security regarding regional cancer care among bereaved families. Variables significantly associated with a higher sense of security in family members of patients that had died due to cancer were the family members' higher age, patient's death at home, better health status of the family at patients' end of life, lower caregiving burden, and elements of perceived good patient death, including being free from physical distress, trusting the physician, living in calm circumstances, and feeling that one's life was fulfilling [11].

Hence, having a sense of security can be of great value for the family member during palliative care, but few studies have focused on variables associated with family members being secure/less secure and previous quantitative research has had a post-loss, cross-sectional design. To further develop palliative care and the support given to family members, it seems valuable to further investigate what variables are related to family members feeling secure or insecure during ongoing palliative care and to study other contexts than the Japanese one, to assist staff members to identify individuals at risk and plan effective support. In addition, to our knowledge, there is no study exploring longitudinal data regarding family members' sense of security. Therefore, we wanted to study what characterises family members feeling secureinsecure during palliative care in a Swedish context, and also to evaluate if there is an association between their sense of security during ongoing care and well-being during bereavement.

\section{Aims}

The aims of the present analyses were: 1) to discover which variables are associated with family members feeling secure during the palliative care period; 2) to develop a model of family members' sense of security during palliative care, and 3) to evaluate if family members' sense of security during ongoing palliative care predicts wellbeing during bereavement.

\section{Main hypotheses}

We hypothesised that the family members' sense of security in palliative care would be related to the family members' demographic characteristics, health-related quality of life, coping, attachment security, perceived situation as a family member of a severely ill person, perceived support from family and friends, sense of security during palliative care and patient characteristics, and inversely related to the family members' perceived stress. These hypotheses were based on previous findings in the literature suggesting that family members' sense of security in palliative care or advanced cancer care is associated with family member demographics, e.g. older age [11], family members' health-related quality of life, e.g. better health status [11], situation as family member of a severely ill person, e.g. better caregiving situation [11]. We also hypothesised that family members' perception of stress and coping, their attachment security, sense of security with care, patient characteristics, and perceived support from family and friends would be associated with family members' sense of security during palliative home care, because such aspects have been found important in relation to patients' sense of security during palliative care [13] or when they have advanced cancer [14], or the general population's feelings of security regarding cancer care [15].

In the longitudinal analysis, we hypothesised that the family members' sense of security in palliative care would be related to the family members' well-being during bereavement in terms of their health-related quality of life, stress and coping, psychological well-being and complicated grief symptoms. The reason for these hypotheses was that previous longitudinal studies of bereaved family members have indicated that well-being 
post-loss can be assessed in terms of health-related quality of life [16], psychological well-being $[15,16]$, stress $[17,18]$, and complicated grief symptoms [19].

\section{Methods \\ Design}

This questionnaire study had two different types of data collection: i) data collected during ongoing palliative care (which were used in the cross-sectional analyses related to aim 1-2); ii) data collected during bereavement (which were used together with the data collected during ongoing palliative care in the predictive analyses related to aim 3).

\section{Participants, procedure and measures}

Details of the data collection have already been published and is briefly summaries here [13, 20]. Family members of patients who were receiving palliative home care were recruited from six palliative home care units in Sweden. The cross-sectional analyses were based on a sample of 227 participants, and the bereavement analyses were based on 158 participants, the demographic characteristics are displayed in Table 1. The data during ongoing palliative care were collected between September 2009 and October 2010, and data 1 year into bereavement were collected 1 year later.

Consent from the participants were collected in three steps:

1. Eligible family members (according to inclusion and exclusion criteria) received oral and written information and was asked (by the health care staff) if they wanted to participate, and to reply by filling in a form (written informed consent). The form was (according to the family member's choice) either returned to the research nurse by the health care staff or posted by the family member to the research nurse in a prepaid envelope.

2. The research nurse then contacted these family members who had provided written informed consent by phone. The research nurse gave more information about the study and checked that the family member still wanted to participate. A date for the interview was also scheduled at the call. ( $99 \%$ of the family members wanted to be interviewed over the phone).

3. Before the interview started (at the set date) the research nurse repeated information about the study, including the right to withdraw at any time without giving any reason, and she also checked that the family member still wanted to participate.

In the form giving informed consent to participate in the study (see Step 1 above), there was also another option of receiving more information from a research nurse before deciding. Those family members that were interested in getting more such information (a minority) were then contacted by phone by the research nurse. She checked if the family member was still interested to get more information. After providing such information, the research nurse asked if the family member wanted to participate, and a date was scheduled for the interview (i.e. Step 2). The family members who then decided to participate were the family members who provided verbal consent only.

Before the actual interview with the participants providing verbal consent only, the research nurse went through Step 3 (see above), that is she checked at the set date, before the interview, that the family member had not changed their mind about participation.

The reason for not asking the family members who provided verbal consent only to send a written informed consent, was to avoid burdening them with an administrative task in the difficult situation of having a severely ill and dying close relative or friend.

The issue that was the focus of this study (i.e. the dependent variable), family members' sense of security during the palliative care period, was assessed by one question constructed by the authors ("How often have you felt secure [during the palliative care period]?"; six-point response-scale, 1 (never) to 6 (always)), and initial analysis regarding construct validity was conducted [20]. We also constructed a question where we asked about how important it was for the family member to sense security with the care of the ill family member ("How important is it for you to sense security with the care of your member?"; four-point Likert scale 1 (Of no importance) to 4 (Of the utmost importance). Regarding content and face validity of these questions, both were considered as valid in relation to the aim of the study by an expert panel of researchers $(n=3)$ and clinicians $(n=6)$.

A pilot study was conducted with four relatives (one during home visits and three through telephone interviews) and they also were asked about the questionnaire and the method of collecting data. This led to corrections to the instructions and minor revisions to some of the questions, but not to the two questions above mentioned.

When we selected questions and instruments, we wanted to be mindful of the family members' situations in having a close family member (i.e. the patient) who was dying or had died during the last year, and therefore short scales or single questions were chosen if feasible. For further information about the measures, see Table 2 and Additional file 1. Most of the data was gathered by a structured interview with the family member (ongoing 
Table 1 Sample characteristics ( $n=227$ ) and analysis of the individual variables in relation to the family members' sense of security during palliative care (dependent variable)

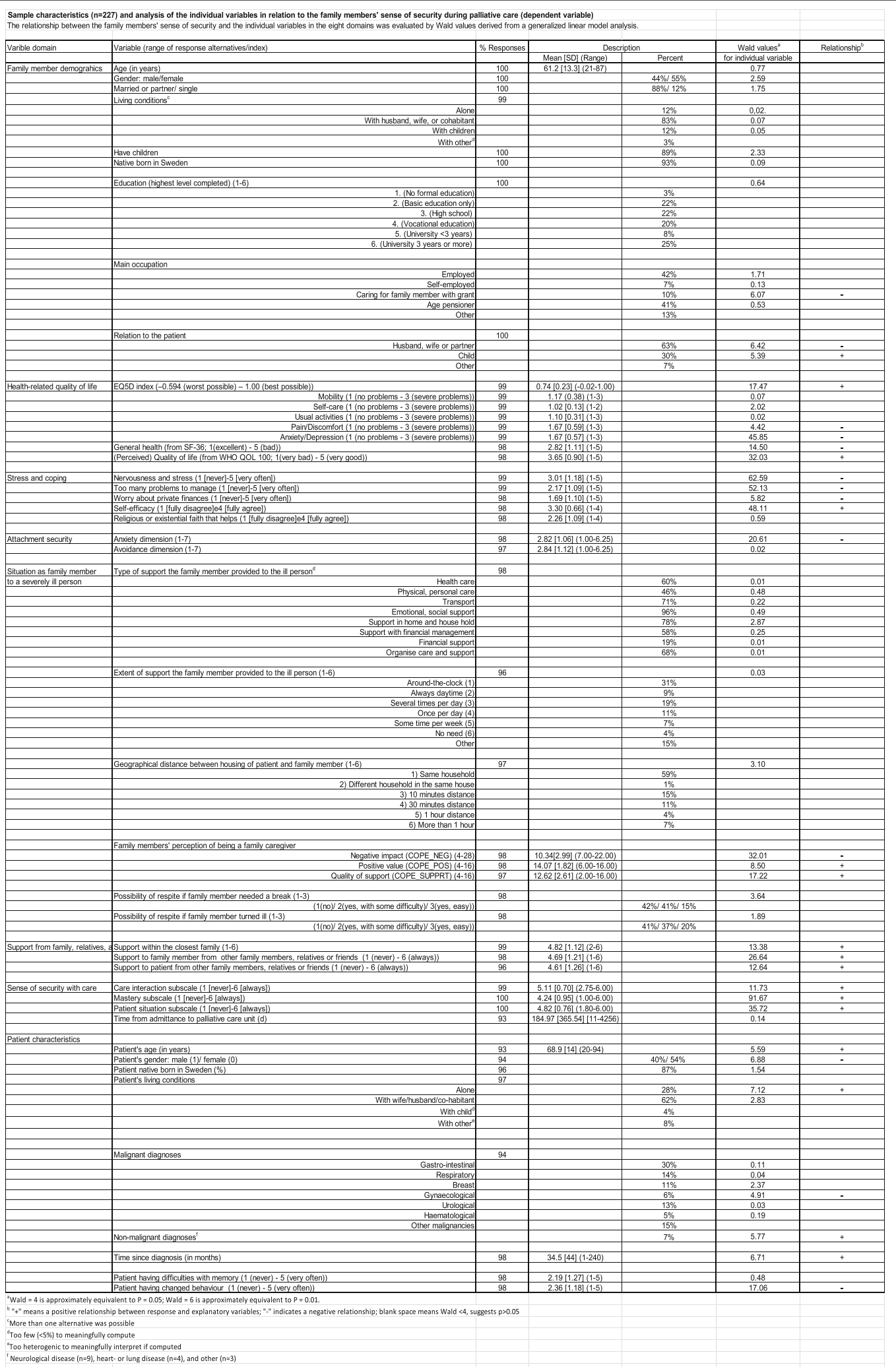


Table 2 Overview of measured variables collected during on-going palliative care and one year after the patient's death

\begin{tabular}{ll}
\hline Variable domain & Measures \\
\hline Family member demographics & $\begin{array}{l}\text { Age, gender, living and family conditions, education, country of birth, relationship to the patie } \\
\text { main occupation }\end{array}$ \\
Health-related quality of life & $\begin{array}{l}\text { The EuroQol-5D (EQ-5D), including five subscales: mobility, self-care, pain, usual activities, and } \\
\text { psychological status; 3-point response scale: } 1 \text { (no problems) - } 3 \text { (severe problems). }\end{array}$
\end{tabular}

An index score was calculated for each respondent's health status: $1=$ full health; $-0.594=$ worstimaginable health state

General quality of life: one question (of 100) from the WHO QOL 100 instrument; 5-point scale: 1 (very poor) - 5 (very good)

General health: one overall question from the SF-36 (a 36-item short-form health survey questionnaire); 5-point scale: 1 (excellent health) - 5 (poor health)

Stress and coping

Attachment security

Situation as family member to a severely ill person

Support from family, relatives, and friends

Sense of security in palliative care

Patient characteristics

Well-being during bereavement
Stress: two (of ten) items from the Perceived Stress Scale (PSS) (felt nervous and "stressed"; difficulties were piling up so high that you could not overcome them); 5-point scale: 0 (never) - 4 (very often)

Worry about personal finances during the last month: 5-point scale: 0 (never) - 4 (very often)

Self-efficacy: One statement (of ten; I can solve most problems if I invest the necessary effort) from the General Self-Efficacy Scale (GSE); 4-point scale: 1 (not at all true) - 4 (exactly true)

Religious or existential belief that helps the informant to cope with problems: One statement; 4point scale: 1 (not at all true) - 4 (exactly true)

the Experiences in Close Relationships scale (ECR-M16); 16 items to measure attachment anxiety (fear of rejection and abandonment) and avoidance (discomfort with closeness and dependence on close others) in close relationships (including non-romantic partners); 7-point scale: 1 (lower attachment insecurity) - 7 (greater attachment insecurity)

Type of support/care the family member provided to the ill person: eight alternatives; yes/no (see Table 1)

Extent of support the family member provided to the ill person: one question; 6-point scale: 1 (around-the-clock) - 6 (no need of support)

Geographical distance between housing of patient and family member: one question; 6-point scale: 1 (same household) - 6 (more than 1-h distance)

The family member's perception of being a family caregiver: the COPE questionnaire: 15 questions; 4 [28] point scale: 1 (never) - 4 (always) based on 3 validated sub-scales: Negative impact scale, Positive value scale and Quality of support scale

Possibility of respite if family member needed a break: one question; 3-point scale: 1 (no) - 2 (yes, with some difficulty) - 3 (yes, easy)

Possibility of respite if family member became ill: one question; 3-point scale: 1 (no) - 2 (yes, with some difficulty) - 3 (yes, easy)

The family member's perception of support from members within the closest family: one question; 6-pointscale: 1 (never) - 6 (always)

The family member's perception of support from other family members, relatives or friends: one question; 6-pointscale: 1 (never) - 6 (always)

The family member's perception of support to patient from other family members, relatives or friends: one question; 6-pointscale: (1 (never) - 6 (always))

The family members' sense of security with palliative care: The sense of security in care-Relatives' Evaluation instrument (15-item instrument (6-point scale: 1 (never) - 6 (always) based on 3 validated sub-scales: Care Interaction (eight items), Mastery (four items) and Patient Situation (three items)

Time (days) from commencement of palliative home care services () to the interview (with the family Medical member)

Demographics: age, gender, living and family conditions, and country of birth.

Diagnosis: the patient's diagnosis and the time since diagnosis.

(Family member's perception of) Patient having difficulties with memory: one questions; 5-point response scale: 1 (never) - 5 (very often)

(Family member's perception of) Patient having changed behavior: one questions; 5-point response scale: 1 (never) - 5 (very often)

The EuroQol-5D (EQ-5D), see above "Health-related quality of life" domain

General quality of life, one question from the WHO QOL 100 instrument, see above records

Medical records

[21]

$*$

*

*

[20]

*

[22] 
Table 2 Overview of measured variables collected during on-going palliative care and one year after the patient's death (Continued)

\begin{tabular}{ll}
\hline Variable domain & Measures \\
\hline & General health: one overall question from the SF-36, see above "Health-related quality of life" domain [23] \\
& Psychological well-being previous 2 weeks: The WHO-5 Well-being Index 6-30 (five items; 6-point \\
& scale: 1 ('at no time') - 6 ('all of the time')) \\
& Stress: two (of ten) items from the Perceived Stress Scale (PSS); see above "Stress and coping" \\
& domain \\
& Had own contact with healthcare because of the death of the patient (that received care by the \\
& palliative care unit); 4-point scale: 1(never) - 4(> 5 times) \\
& Complicated grief symptoms: Inventory of complicated grief screen (ICGS) is a 9-item shortened \\
& version of the original ICG; 5-point scale: 1(never) - 5(always) \\
[30, 31]
\end{tabular}

*Questionnaire developed by the authors

care and 1 year after the patient's death) using questionnaires that were administered verbally, and some data were collected via the palliative care team, for example the patients' diagnoses.

\section{Statistical analyses}

An assessment of missing data did not indicate any systematic patterns, and the number of missing values was small, ( $0 \%$ (e.g. on the dependent variable, i.e. the Family members' feeling of security during the palliative care period) - 6\% (13/227; Patient's age (in years)). Where there were missing values, the specific analysis was performed with this respondent's information excluded, although the respondent could be included in other analyses.

Because of the substantial number of independent variables in the cross-sectional analyses and the possibility of over-fitting the model, the variables that were hypothetically important to the family members' sense of security during ongoing palliative care (the dependent variable) were gathered into eight domains. The domains were then managed as steps in the analyses, lowering the total of variables tested in one particular test. The eight domains with possible association to family members' sense of security during ongoing palliative care were assessed by the variables listed in Table 2. This table also shows the variables that were collected as indicators of family members' well-being during bereavement and of hypothesized predictors.

Descriptive statistics were conducted for the individual variables in the eight domains. The relationship between family members' sense of security and the independent variables in the eight domains was evaluated by Wald values derived from the generalised linear model analysis with ordinal multinomial distribution and logit link or normal identity. In this type of model, the dependent variable is treated as an ordinal multinomial variable (as opposed to categorical or linear/continuous variable), which best reflected the nature of the dependent variable in our response data (i.e. a six-point response-scale).
Wald $=4$ is approximately equivalent to $P=0.05$, and Wald $=6$ is approximately equivalent to $P=0.01$. The Akaike Information Criterion (AIC) was used in the model-building analyses [32]. The AIC offers a relative measure of the information lost when a given model is applied to illustrate reality. The simplest best model with the smallest information loss when predicting the outcome gives the lowest AIC value.

As the first step (Step 0) in the model-building process, one analysis per domain was carried out, and its AIC was used to determine in which sequence the domains should be added in the subsequent stepwise procedure. Only variables with Wald values $>2$ were allowed to be tried in the further model-building. This Wald value corresponds to approximately $p<0.15$; hence, a generous selection criterion was preferred, to reduce the risk of discarding variables that could have been valuable in further model-building. The domain with the lowest AIC was taken first in the model-building analyses and the domain with the highest AIC was taken last, because a lower AIC value signals a higher value of explanation. The final step in the process was performed using the best subset analyses with AIC. Classification of the developed model was calculated and the percentage of correct classifications of the observed cases was computed. In addition, we made statistical comparisons between the family members who took part and those who declined to participate (chi-square and ttest). Statistical tests were two-tailed with alpha set at 0.05 . The data were analysed using Statistica, Version 10 (Statsoft Inc., USA).

\section{Results}

The respondents' ratings of their sense of security during palliative care ranged from 1 (never) to 6 (always), with a mean value of 4.11 (standard deviation (SD) 1.27). When asked about how important it was for the family member to sense security with the care of the (ill) family member, i.e. the patient receiving palliative home care, the ratings ranged from 3 (Of 
great importance) to 4 (Of the utmost importance), with a mean value of 3.9 (SD 0.31).

\section{Aim 1: family members' sense of security during ongoing palliative care}

According to the analysis of the individual variables, all hypothesised domains were significantly related to the dependent variable, i.e. to the family members' sense of security during palliative care.

The following 16 variables were positively related to family members' sense of security during ongoing palliative care (presented in order of decreasing Wald values; 91.67-5.39): Mastery subscale (SEC-R); Self-efficacy; Patient Situation subscale (SEC-R); (Perceived) Quality of life; (Perceived) Support to family member from other family members, relatives or friends; EQ5D index; Quality of support (COPE_SUPPORT); (Perceived) Support within the closest family; (Perceived) Support to patient from other family members, relatives or friends; Care interaction subscale (SEC-R); Positive value of being a family caregiver (COPE_POS); Patient living alone; Time since diagnosis; Patient having a non-malignant diagnosis; Patient's age; and Family member being a child to the patient.

The following 13 variables were negatively related to family members' sense of security during ongoing palliative care (presented in order of decreasing Wald values; 62.59-4.42): Family member being nervous and feeling stress; Family member perceiving too many problems to manage; Anxiety/Depression subscale; Negative perception of the impact of being a family caregiver (COPE_ NEG); Attachment anxiety; Patient having changed behaviour; Family member's general health; Patient being male; Family member being husband, wife or partner to the patient; Family member caring for the patient with grant; Family member's worry about private finances;
Patient having gynaecological cancer; and Family member's pain/discomfort.

\section{Aim 2: model-building}

Model-building began with one analysis per domain. Only the variables with Wald $>2$ were chosen for further analyses in the steps. The AIC for the eight domains resulted in "Sense of security with care" domain was entered first in the stepwise procedure, and "Family member demographics" domain last.

The stepwise model-building process resulted in a model with the following five variables (presented in order of decreasing Wald values): i) Mastery subscale 48.44 ; 2) Nervousness and stress 18.84 ; 3) Self-efficacy 13.32; 4) (Patient having) Gynaecological cancer 9.46; 5) (Perceived) Quality of life 3.40 (Table 3).

Of the 209 respondents used in the selected model, the correct response alternatives were predicted in 55\%, with a range from the individual response alternatives from $0 \%$ (1 (never) as 1 (never) to 60\% (4 (often) as 4 (often)). A correct response plus minus one response alternative (e.g., response alternative 5 (very often) as 4 (often), 5 (very often) or 6 (always)) was predicted in $91 \%$. It seems important to avoid the risk of overestimating a family member's sense of security; therefore, a correct response minus 1 response alternative (e.g., response alternative 5 (very often) as either 4 (often) or 5 (very often) was calculated: $68 \%$.

\section{Aim 3: family members' sense of security during ongoing palliative care as a predictor of well-being during bereavement}

The family members' sense of security during ongoing palliative care predicted ten variables collected 1 year after the patient's death (see Table 4). Three of these variables were positively related to the family members'

Table 3 Final model in the stepwise model-building process

\begin{tabular}{|c|c|c|c|}
\hline Varible domain & Variable & $\begin{array}{l}\text { Wald values }{ }^{a} \text { for partial regression coefficients in the } \\
\text { final best subset }\end{array}$ & Relationship $^{b}$ \\
\hline $\begin{array}{l}\text { Sense of security with } \\
\text { care }\end{array}$ & Mastery subscale (SEC-R; 1 [never] - 6 [always]) & 48.44 & + \\
\hline \multirow[t]{2}{*}{ Stress and coping } & $\begin{array}{l}\text { Nervousness and stress (from PSS; } 1 \text { [never] - } 5 \text { [very } \\
\text { often]) }\end{array}$ & 18.84 & - \\
\hline & $\begin{array}{l}\text { Self-efficacy (from GSE; } 1 \text { [fully disagree] - } 4 \text { [fully } \\
\text { agree]) }\end{array}$ & 13.32 & + \\
\hline Patient characteristics & Gynecological cancer & 9.46 & - \\
\hline $\begin{array}{l}\text { Health-related quality } \\
\text { of life }\end{array}$ & $\begin{array}{l}\text { Quality of life (from WHO QOL 100; } 1 \text { (very bad) - } 5 \\
\text { (very good)) }\end{array}$ & 3.40 & + \\
\hline
\end{tabular}

A model was developed with the family members' sense of security during ongoing palliative care as the dependent variable, and the variables in the eight domains as independent variables

${ }^{a}$ Wald $=4$ is approximately equivalent to $P=0.05$; Wald $=6$ is approximately equivalent to $P=0.01$

bu+" means a positive relationship between response and explanatory variables; "-" indicates a negative relationship 
Table 4 Characteristics and longitudinal analysis of the individual variables' relation to the family members' sense of security during ongoing palliative care (independent variable)

\begin{tabular}{|c|c|c|c|c|c|}
\hline Varible domain & Variable (range of response alternatives/index) $n=158$ & $\begin{array}{l}\% \\
\text { Responses }\end{array}$ & $\begin{array}{l}\text { Description Mean }[S D] \\
\text { (Range) or Percent }\end{array}$ & $\begin{array}{l}\text { Wald } \\
\text { values }^{\mathrm{a}}\end{array}$ & $\begin{array}{l}\text { Relation- } \\
\text { ship }^{\mathrm{b}}\end{array}$ \\
\hline \multirow[t]{13}{*}{$\begin{array}{l}\text { Wellbeing during } \\
\text { bereavement }\end{array}$} & $\begin{array}{l}\text { Health-related quality of life: EQ5D index (-0.594 (worst } \\
\text { possible) - } 1.00 \text { (best possible)) }\end{array}$ & 100 & $0.78(0.23[-0.041-1.00])$ & 5.74 & + \\
\hline & Mobility (1 (no problems) - 3 (severe problems)) & 100 & $1.21(0.41[1-2])$ & 0.60 & \\
\hline & Self-care (1 (no problems) - 3 (severe problems)) & 100 & $1.02(0.14[1-2])$ & 2.00 & \\
\hline & Usual activities (1 (no problems) - 3 (severe problems)) & 100 & $1.08(0-30[1-3])$ & 0.01 & \\
\hline & Pain/Discomfort (1 (no problems) - 3 (severe problems)) & 100 & $1.63(0.60[1-3])$ & 3.91 & - \\
\hline & Anxiety/Depression (1 (no problems) - 3 (severe problems)) & 100 & $1.47(0.55[1-3])$ & 17.60 & - \\
\hline & General health (from SF-36; 1 (excellent) - 5 (bad)) & 100 & $2.85(1.11[1-5])$ & 7.45 & - \\
\hline & $\begin{array}{l}\text { Quality of life (from WHO QOL 100; } 1 \text { (very bad) - } 5 \text { (very } \\
\text { good)) }\end{array}$ & 100 & $4.03(0.89[1-59)$ & 14.95 & + \\
\hline & $\begin{array}{l}\text { Nervousness and stress (from Perceived Stress Scale; } 1 \text { (never) } \\
-5 \text { (very often)) }\end{array}$ & 100 & $2.48(1.21](1-5)$ & 17.26 & - \\
\hline & $\begin{array}{l}\text { Too many problems to manage (from General Self-Efficacy } \\
\text { Scale; } 1 \text { (never) -5 (very often)) }\end{array}$ & 99 & $1.64(0.97[1-5])$ & 5.94 & - \\
\hline & $\begin{array}{l}\text { Psychological well-being (WHO-wellbeing index; 6-30; } 1 \text { (at } \\
\text { no time) -6 (all of the time)) }\end{array}$ & 100 & 20.87 (5.83 [6-30]) & 23.75 & + \\
\hline & $\begin{array}{l}\text { Had own contact with health care because of the death of } \\
\text { the patient }\end{array}$ & 99 & $1.49[0.91](1-4)$ & 12.23 & - \\
\hline & $\begin{array}{l}\text { Complicated grief symptoms (Inventory of complicated grief } \\
\text { screen; } 1 \text { (never) -5 (always)) }\end{array}$ & 100 & $2.41(0.77(1-4.56])$ & 23.55 & - \\
\hline
\end{tabular}

The relationships between the family members' sense of security and the individual variables were evaluated by Wald values derived from a generalized linear model analysis

${ }^{\mathrm{a}}$ Wald $=4$ is approximately equivalent to $P=0.05$; Wald $=6$ is approximately equivalent to $P=0.01$

b " + " means a positive relationship between response and explanatory variables; "-" indicates a negative relationship

sense of security during ongoing palliative care (presented in order of decreasing Wald values; 23.75-5.74): Psychological well-being; (Perceived) Quality of life; Health-related quality of life.

The following seven variables were negatively related to family members' sense of security during ongoing palliative care (presented in order of decreasing Wald values; 23.55-3.91): Complicated grief symptoms; Anxiety/Depression; Nervousness and stress; Contact with health care post-loss because of the death of the patient; General health; Too many problems to manage; Pain/ Discomfort.

\section{Discussion}

This study showed that the family members rated their sense of security during palliative care rather high (mean 4.11 (Likert-type score 1-6), and they perceived a sense of security during ongoing palliative care of great or utmost importance (mean 3.9 of maximum 4 (=utmost)). All the hypothesised domains (i.e. the family members' demographic characteristics, health-related quality of life, stress, coping, attachment security, perceived situation as a family member of a severely ill person, perceived support from family and friends, sense of security during palliative care and patient characteristics) were significantly related to the family members' sense of security during the palliative home care period, and we developed a (cross-sectional) model for prediction of such a sense. In addition, the longitudinal analysis showed that the family members' well-being 1 year after the patient's death was predicted by their sense of security during ongoing palliative care.

The developed model pointed out that family members sensing less security during ongoing palliative care also rated lower mastery, higher nervousness and stress, lower self-efficacy and lower health-related quality of life. These results have support in the previous literature $[11,13-15]$, although family members' ages were not associated with their sense of security, as in Igarachi et al.'s study [12].

As the same, or very similar, questions were posed to patients in a parallel study (with focus on patients' sense of security during palliative care) [13] and were analysed with similar methods, it is worthwhile to point out the variables that were selected in both FC and patient models: perception of nervousness and stress; self-efficacy; and patients having gynaecological cancer. The patient model also included "worrying about personal finances", and "avoidance", while the FC model comprised FC mastery and FC 
perceived quality of life as well. Although patients and FC seem to share several aspects related to their sense of security during palliative care, there are also differences to be recognised by the health care staff.

Moreover, the findings indicate that the content of a single question on the family members' sense of security is of significance to their situation and of relevance for palliative care. The Mastery subscale had the highest Wald value of the selected variables in the model. This subscale, one of three in the Sense of Security in Care - Relatives' Evaluation (SEC-R) instrument [20], includes questions on e.g. the family member's feelings of control, of ability to be oneself when interacting with the patient's health care personnel and of ability to do what is most important in daily life given the patient's health and care. In clinical practice, attention and support to such dimensions may facilitate the family member's sense of security, and when appropriate it seems of value to initiate a dialogue with the family member about such issues.

The final model also included a fifth variable, namely the patient having gynaecological malignancy. However, there were only 13 family members in the study population whose ill family member (the patient) had such a diagnosis. These results should, therefore, be interpreted with caution, and the importance of gynaecological malignancy on family members' sense of security during palliative care needs further study.

Four of the hypothesised domains - Family members demographics; Attachment (in)security; Situation as family member to a severely ill person; (Lack of) Support from family, relatives and friends - were not represented in the final model, but showed significant associations with the family members' sense of security in the bivariate analysis. These findings also seem of importance when clinicians want to identify family members at risk of sensing low security during ongoing palliative care.

Although the mean value of the family members' ratings of their sense of security during palliative care was rather high (as pointed out above), it is interesting that the mean value seems somewhat lower than when patients during ongoing palliative care responded to the same question (4.6 (SD 1.19)) [13] . These results are in line with previous research showing higher anxiety levels in family members compared to patients in palliative care [33, 34].

Finally, we want to draw attention to the results of the longitudinal analysis suggesting that the family members' well-being (e.g. in terms of psychological well-being, complicated grief symptoms, quality of life) 1 year after the patient's death was predicted by their sense of security during ongoing palliative care. Previous studies have identified risk factors for negative adjustment to bereavement (e.g. a closer relationship to the deceased, socioeconomic disadvantage) as well as positive factors for reduced risk (e.g. positive high-quality social support, caregiver report of needs met) [35-39]. Moreover, instruments to identify family members at risk for developing bereavement-related mental health challenges pre- or post-loss have been developed (e.g. Family Relationships Index (FRI) [40] and the Bereavement Risk Inventory and Screening Questionnaire (BRISQ)) [37], and pre-loss screening as well as interventions initiated pre-loss have been advocated to facilitate caregivers' return to normal life as soon and as effectively as possible [41, 42]. To our knowledge, no study with a quantitative design has previously focused on sense of security as a possible pre-loss resilient factor during the delivery of the patient care. According to the present findings, family members' sense of security while the patient is still alive should be further studied to clarify its role with regard to such outcomes and possible future systematic implementation in clinical practice.

\section{Limitations}

One part of the study had a cross-sectional design, and, thus, the observed associations among these variables collected during ongoing palliative care may not be causal. Moreover, the mean value of the family members' sense of security scores was rather high, which may limit the conclusion that can be drawn about populations with low scores on this measure. In addition, $93 \%$ of the responders were born in Sweden. Research is needed to examine the sense of security during palliative care especially among vulnerable groups of family members, including those with limited ability to communicate verbally with health care staff.

Also, data is collected 8 years back in time. During that time period there has not been any large changes regarding the organisation of the palliative care, possibly it has expanded to patients with non-malignant diseases, and the length of stay in hospital has become shorter since the data were collected. This makes it more important to recognise patients and family members needs in the palliative homecare context.

Finally, single questions may contribute with limitations of the study. Although most of these questions were selected from valid and reliable instruments, a few were constructed by the authors, including the question about family members' sense of security. As psychological phenomena are usually not directly measurable, multiple item scales are often used to approximate a measure of the concept and to partly manage the effect of measurement error. However, at the time of the study there were, to our knowledge, no such multiple item scales to measure the study phenomenon. The single 
questions that were used were validated prior to the study concerning their content and face validity, but not statistically scrutinized concerning their construct and estimation of measurement error and this may have implications for the interpretations of the results.

\section{Conclusion}

This study has identified several variables associated with family members having a sense of security during palliative care, and also developed a model for statistical prediction of such sense. Based on our findings, a single question about the family members' sense of security during ongoing palliative care that predicted their wellbeing 1 year after the patients' death may be a contribution to such development.

Moreover, future research should also explore effective interventions to support family members during ongoing palliative care as well as to prevent negative adjustment to bereavement. Although our study was not an intervention study, the factors identified as associated with the family members' sense of security during ongoing care may inform the design of such future interventions.

\section{Additional file}

Additional file 1: information Questionnaire developed by the authors. (DOCX $24 \mathrm{~kb})$

\section{Abbreviations}

AIC: Akaike Information Criterion; ECR-M16: Experiences in Close Relationships scale; EQ-5D: The EuroQol-5D; GSE: General Self-Efficacy Scale; ICGS: Inventory of complicated grief screen; PSS: Perceived Stress Scale; SF36: 36-item short-form health survey questionnaire

\section{Acknowledgements}

The authors thank the participating family members and the staff at the study units for their help.

\section{Authors' contributions}

AM: Performed study procedures and collection of data, analysis of data, and was responsible for drafting and editing of the manuscript. BK: Participated in the conception and design of the study, analysis of data, and took part in drafting and editing of the manuscript. ML: Participated in interpretation of data, as well as drafting and revising the manuscript. All authors read and approved the final manuscript.

\section{Funding}

This work was supported by the Medical Research Council of Southeast Sweden [grant number LIO-126821], the Swedish Society of Medicine [grant number 2008-21732], FAS (Swedish Council for Working Life and Social Research [grant number 2006-1621]), the County Council in Östergötland [grant number FORSS-147851], Sweden and 'Konung Gustaf V:s och Drottning Victorias Frimurarestiftelse [grant number 104821]. The funders had no role in the design of the study, data collection and analysis, decision to publish or preparation of the manuscript.

\section{Availability of data and materials}

Data origin from the "Upplevelse av trygghet hos patienter respektive anhöriga vid palliativ vård" study. Ethical restrictions prevent this data from being deposited in a public repository. The data are available upon request, and requests can be sent to the authors.

\section{Ethics approval and consent to participate}

The regional board of ethics ("Regionala etikprövningsnämnden i Linköping, Avdelningen för prövning av. övrig forskning") approved the study (Dnr:14406 (2007-02-09), Dnr:144:06 T100 (2007-12-11); Dnr 2010/278-31 (2010-12-14). The participants completed a consent form at the beginning of the study and then provided verbal consent during the interview step of the study.

\section{Consent for publication}

Not applicable.

\section{Competing interests}

The authors declare that they have no competing interests.

\section{Author details}

${ }^{1}$ Department of Medical and Health Sciences, Linköping University, Linköping, Sweden. ${ }^{2}$ Department of Advanced Home Care and Department of Medical and Health Sciences, Linköping University, Norrköping, Sweden. ${ }^{3}$ Centre for Clinical Research Sörmland, Uppsala University, Eskilstuna, Sweden. ${ }^{4}$ Medical Department, Mälarsjukhuset Hospital, 63188 Eskilstuna, Sweden.

Received: 11 February 2019 Accepted: 11 July 2019

Published online: 25 July 2019

\section{References}

1. Trevino KM, Prigerson HG, Maciejewski PK. Advanced cancer caregiving as a risk for major depressive episodes and generalized anxiety disorder. Psychooncology. 2018;27:243-9.

2. Lundberg T, Olsson M, Furst CJ. The perspectives of bereaved family members on their experiences of support in palliative care. Int J Palliat Nurs. 2013;19:282-8

3. Milberg A, Strang P. What to do when 'there is nothing more to do'? A study within a salutogenic framework of family members' experience of palliative home care staff. Psychooncology. 2007;16:741-51.

4. Stajduhar K, Funk L, Jakobsson E, Ohlen J. A critical analysis of health promotion and 'empowerment' in the context of palliative family caregiving. Nurs Inq. 2010;17:221-30.

5. Klarare A, Rasmussen BH, Fossum B, et al. Experiences of security and continuity of care: Patients' and families' narratives about the work of specialized palliative home care teams. Palliat Support Care. 2017;15:181-9.

6. Larsson BJ, Frojd C, Nordin K, Nygren I. Relatives of patients with amyotrophic lateral sclerosis: their experience of care and support. Palliat Support Care. 2015;13:1569-77

7. Funk LM, Allan DE, Stajduhar KI. Palliative family caregivers' accounts of health care experiences: the importance of "security". Palliat Support Care. 2009:7:435-47.

8. Akiyama M, Hirai K, Takebayashi T, et al. The effects of community-wide dissemination of information on perceptions of palliative care, knowledge about opioids, and sense of security among cancer patients, their families, and the general public. Support Care Cancer. 2016;24:347-56.

9. Goldschmidt D, Schmidt L, Krasnik A, Christensen U, Groenvold M. Expectations to and evaluation of a palliative home-care team as seen by patients and carers. Support Care Cancer. 2006;14:1232-40.

10. Milberg A, Wahlberg $R$, Jakobsson $M$, et al. What is a 'secure base' when death is approaching? A study applying attachment theory to adult patients' and family members' experiences of palliative home care. Psychooncology. 2012;21:886-95.

11. Öhlen J, Andershed B, Berg C, et al. Relatives in end-of-life care - part 2: a theory for enabling safety. J Clin Nurs. 2007;16:382-90.

12. Igarashi A, Miyashita M, Morita T, et al. Association between bereaved Families' sense of security and their experience of death in Cancer patients: cross-sectional population-based study. J Pain Symptom Manag. 2016;51:926-32.

13. Milberg A, Friedrichsen $M$, Jakobsson $M$, et al. Patients' sense of security during palliative care-what are the influencing factors? J Pain Symptom Manag. 2014;48:45-55

14. Akiyama M, Takebayashi T, Morita T, et al. Knowledge, beliefs, and concerns about opioids, palliative care, and homecare of advanced cancer patients: a nationwide survey in Japan. Support Care Cancer. 2012;20:923-31. 
15. Igarashi A, Miyashita M, Morita T, et al. A scale for measuring feelings of support and security regarding cancer care in a region of Japan: a potential new endpoint of cancer care. J Pain Symptom Manag. 2012;43:218-25.

16. Song JI, Shin DW, Choi JY, et al. Quality of life and mental health in the bereaved family members of patients with terminal cancer. Psychooncology. 2012;21:1158-66.

17. Kim Y, Carver CS, Spiegel D, Mitchell HR, Cannady RS. Role of family caregivers' self-perceived preparedness for the death of the cancer patient in long-term adjustment to bereavement. Psychooncology. 2017;26:484-92.

18. Rumpold T, Schur $S$, Amering $M$, et al. Hope as determinant for psychiatric morbidity in family caregivers of advanced cancer patients. Psychooncology. 2017;26:672-8.

19. Wilson DM, Dhanji N, Playfair R, et al. A scoping review of bereavement service outcomes. Palliat Support Care. 2017;15:242-59.

20. Krevers B, Milberg A. The sense of security in care--Relatives' evaluation instrument: its development and presentation. J Pain Symptom Manag. 2015;49:586-94.

21. Brooks R. EuroQol: the current state of play. Health Policy. 1996;37:53-72

22. TheWHOQOLgroup. The World Health Organization quality of life assessment (WHOQOL) development and general psychometric properties. Soc Sci Med. 1998;46:1569-85.

23. Brazier JE, Harper R, Jones NM, et al. Validating the SF-36 health survey questionnaire: new outcome measure for primary care. BMJ. 1992;305:160-4.

24. Cohen S, Kamarck T, Mermelstein R. A global measure of perceived stress. J Health Soc Behav. 1983;24:385-96.

25. Bosscher RJ, Smit JH. Confirmatory factor analysis of the general self-efficacy scale. Behav Res Ther. 1998;36:339-43.

26. Love J, Moore CD, Hensing G. Validation of the Swedish translation of the general self-efficacy scale. Qual Life Res. 2012;21:1249-53.

27. Lo C, Walsh A, Mikulincer M, et al. Measuring attachment security in patients with advanced cancer: psychometric properties of a modified and brief experiences in close relationships scale. Psychooncology. 2009;18:490-9.

28. Balducci C, Mnich E, McKee K, et al. Negative impact and positive value in caregiving: validation of the COPE index in a six-country sample of carers. Gerontologist. 2008;48:278-86.

29. World Health Organization. Regional Office for Europe C, Denmark. In: Wellbeing measures in primary health care/The DepCare Project: Report on a WHO meeting. Stockholm; 1998. p. 12-3.

30. Field NP, Filanosky C. Continuing bonds, risk factors for complicated grief, and adjustment to bereavement. Death Stud. 2010;34:1-29.

31. Prigerson $\mathrm{HG}$, Jacobs SC. Traumatic grief as a distinct disorder: a rationale, consensus criteria, and a preliminary empirical test. In: Stroebe MS, Stroebe W, Shut $\mathrm{H}$, editors. Handbook of bereavement research: consequences, coping, and care. Washington DC: American Psychological Association; 2002. p. 613-45.

32. Akaike $\mathrm{H}$. A new look at the statistical model identification. IEEE Trans Automativ Control. 1974;19:716-23.

33. Jacobs JM, Shaffer KM, Nipp RD, et al. Distress is interdependent in patients and caregivers with newly diagnosed incurable cancers. Ann Behav Med. 2017;51:519-31.

34. Nipp RD, El-Jawahri A, Fishbein JN, et al. Factors associated with depression and anxiety symptoms in family caregivers of patients with incurable cancer. Ann Oncol. 2016;27:1607-12.

35. Burns E, Prigerson HG, Quinn SJ, Abernethy AP, Currow DC. Moving on: factors associated with caregivers' bereavement adjustment using a random population-based face-to-face survey. Palliat Med. 2018;32:257-67.

36. Nielsen MK, Neergaard MA, Jensen $A B$, et al. Predictors of complicated grief and depression in bereaved caregivers: a Nationwide prospective cohort study. J Pain Symptom Manag. 2017;53:540-50.

37. Roberts K, Holland J, Prigerson HG, et al. Development of the bereavement risk inventory and screening questionnaire (BRISQ): item generation and expert panel feedback. Palliat Support Care. 2017;15:57-66.

38. Roulston A, Campbell A, Cairnduff V, et al. Bereavement outcomes: a quantitative survey identifying risk factors in informal carers bereaved through cancer. Palliat Med. 2017;31:162-70.

39. Lee YJ, Choi YS, Hwang IC, Kim HM, Hwang SW. Resilience at the end of life as a predictor for Postloss growth in bereaved caregivers of Cancer patients: a prospective pilot study. J Pain Symptom Manag. 2016;51:e3-5

40. Edwards B, Clarke V. The validity of the family relationships index as a screening tool for psychological risk in families of cancer patients. Psychooncology. 2005;14:546-54.

41. Kuo SC, Chou WC, Chen JS, et al. Longitudinal changes in and modifiable predictors of the prevalence of severe depressive symptoms for family caregivers of terminally ill Cancer patients over the first two years of bereavement. J Palliat Med. 2017;20:15-22.

42. Kissane DW, Zaider TI, Li Y, et al. Randomized controlled trial of family therapy in advanced Cancer continued into bereavement. J Clin Oncol. 2016:34:1921-7.

\section{Publisher's Note}

Springer Nature remains neutral with regard to jurisdictional claims in published maps and institutional affiliations.
Ready to submit your research? Choose BMC and benefit from:

- fast, convenient online submission

- thorough peer review by experienced researchers in your field

- rapid publication on acceptance

- support for research data, including large and complex data types

- gold Open Access which fosters wider collaboration and increased citations

- maximum visibility for your research: over $100 \mathrm{M}$ website views per year

At BMC, research is always in progress.

Learn more biomedcentral.com/submissions 